\title{
No immediate plans to build new CMA HQ
}

\author{
Cite as: CMAJ 2017 July 17;189:E948-9. doi: 10.1503/cmaj.1095449
}

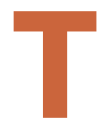
he once-celebrated, modernist Canadian Medical Association (CMA) national headquarters in Ottawa is no longer standing. With the CMA House demolished last fall, the Ottawa site is currently a fenced-in vacant lot. And plans to rebuild are now up in the air, leading some to question the justification for tearing it down in the first place.

CMA representatives said last year that the association would be erecting a new structure on the property; they'd put out a request for proposals and selected an architecture firm. But the deal appears to have fallen through.

In an emailed statement, CMA media spokesperson Ziad Saab wrote, "as of now, there are no plans for construction of a new building." Still, the CMA "intends to retain ownership" of the property at 1867 Alta Vista Drive, according to Saab. He adds the organization is continuing "to explore future options for its use." No one at the CMA agreed to be interviewed.

In May 2016, CMA CEO Tim Smith told CMAJ that "the costs to renovate were close to, if not more than, tearing down and rebuilding. And the reason [for the demolition] is because the building codes have changed so much." Smith did not make the consultant's analysis public. In the recent statement, Saab explained that the problems with the building "posed escalating safety concerns for staff" and "the cost for remediation and renovation proved to be prohibitive."

Despite this explanation, not everyone agrees the building needed to be demol-

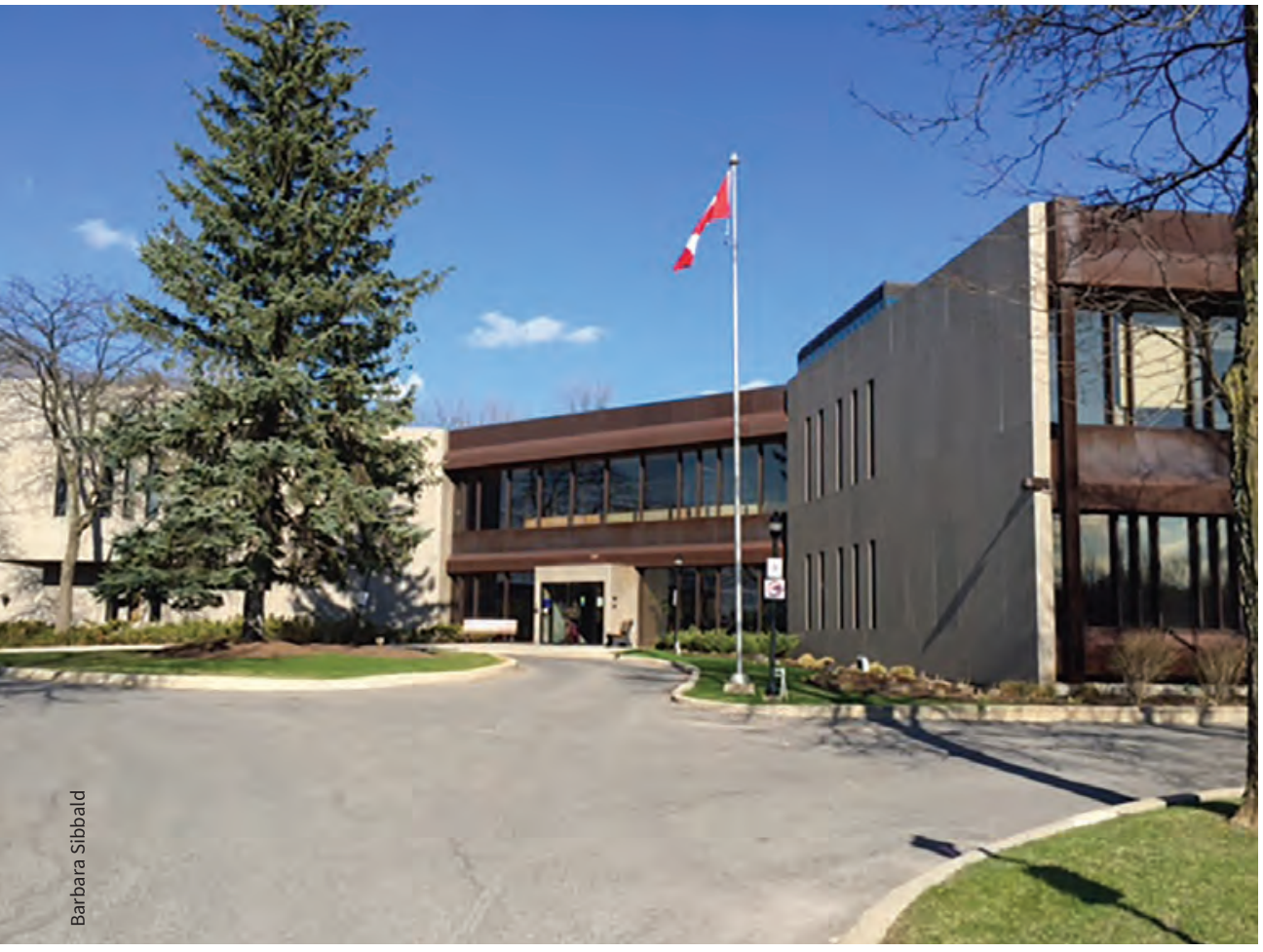

CMA House, a 43000 square foot modernist structure which opened in 1970, was demolished in 2016 due to high renovation costs. A new structure was slotted to be built. ished. Robert Smythe, an urban planning writer in Ottawa, said "I wonder how realistic and costed the plans for a new building actually were. The CMA's destruction of a landmark building, the environmental wastage, and their abandonment of an architecturally distinctive presence in the national capital is deeply disappointing."

Allan Teramura, an Ottawa architect and past president of the Royal Architectural Institute of Canada, also thinks the CMA acted in haste. The tear down was "an affront to the leadership of the people who built it, who thought they were making an investment for the future," he says. "It's like committing doctor-assisted suicide on someone who has a good prognosis."

At the time it was being constructed, the CMA described the building, designed by architecture firm Webb Zerafa Menkes Housden, as a "balance between respect for tradition and a strong emphasis on the future."

CMA employees are currently working in office space in the east end of Ottawa and will later this year be moved to the MD Financial management building at 1870 Alta Vista, across from the site of the former headquarters, which, according to Saab, provides sufficient office space for CMA staff.

Though in need of costly repairs, the CMA House, with its Brutalist and International style aspects, was well loved by architecture buffs. "It was almost suburban in its setting," says Annmarie Adams, an architectural history professor at McGill University. "It had a kind of swanky, Mad Men appeal."

"It was built with fairly high quality materials that are not commonly used anymore," says Teramura. The Corten steel cladding was one such material. It's treated so that it will corrode, but only on the surface, creating a unique - but expensive-rust look. 


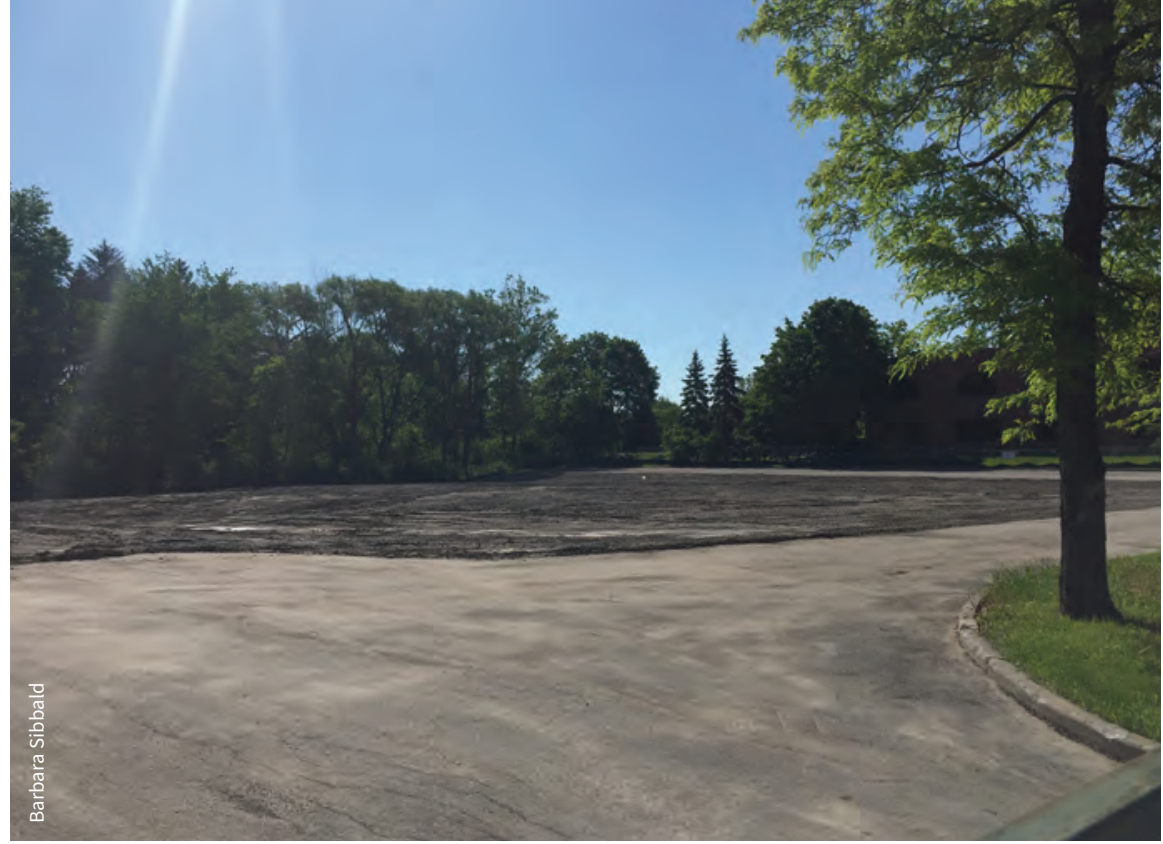

CMA House is demolished, but there are now no plans to rebuild.

However, Teramura at the Royal Architectural Institute of Canada is not particularly surprised by the decision. The building was 46 years old, making it "old enough to have some costly issues, but not old enough to be venerated and worthy of investment." If the building was 80 years old, Teramura says, there likely would have been enough public outcry to save it.

The move is part of a larger trend for major institutions to cut spending on public-facing architecture, says Teramura. With banks, for example, "they used to be important buildings in neighbourhoods," he says. "Nowadays they rent space in commercial buildings and don't give much thought to having a presence on the street," he says.

At one time, medical associations were also among society's contributors to city jewels. As one example, Adams points to the 12-storey Art Deco structure built by the British Medical Association in Sydney, Australia, still revered today. The building "stood for the strong presence of British medicine in Australia, something like a business club," Adams said.

The American Medical Association is investing in its street presence even today. In 2011, it moved into a 1960 landmark building designed by Ludwig Mies van der Rohe, situated on the Chicago River.

Whatever the CMA decides to do with the vacant lot, the former CMA House sets a high bar for design. "It had a very dignified presence about it," says Teramura.

Wendy Glauser, Toronto, Ont. 